Portland State University

PDXScholar

1978

\title{
Material-specific processes in tactile short-term memory
}

Christina Anne Meyers

Portland State University

Follow this and additional works at: https://pdxscholar.library.pdx.edu/open_access_etds

Part of the Cognitive Neuroscience Commons, and the Cognitive Psychology Commons Let us know how access to this document benefits you.

\section{Recommended Citation}

Meyers, Christina Anne, "Material-specific processes in tactile short-term memory" (1978). Dissertations and Theses. Paper 2736.

https://doi.org/10.15760/etd.2732

This Thesis is brought to you for free and open access. It has been accepted for inclusion in Dissertations and Theses by an authorized administrator of PDXScholar. Please contact us if we can make this document more accessible: pdxscholar@pdx.edu. 
AN ABSTRACT OF THE THESIS OF Christina Anne Meyers for the Master of Science in Fsychology presented May 30, 1978.

Title: Material-specific Processes in Tactile Short-term Memory APFKOVED BY MEMBERS OF THE THESIS COMMITTEE:

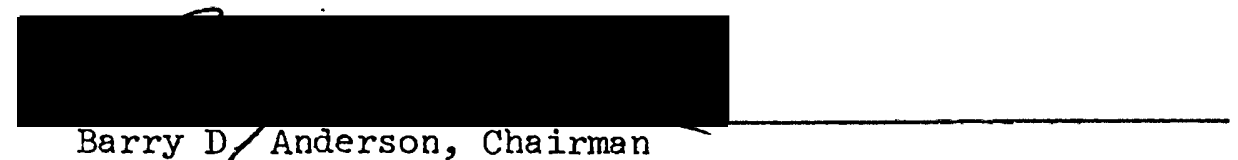
Barry D/Anderson, Chairman

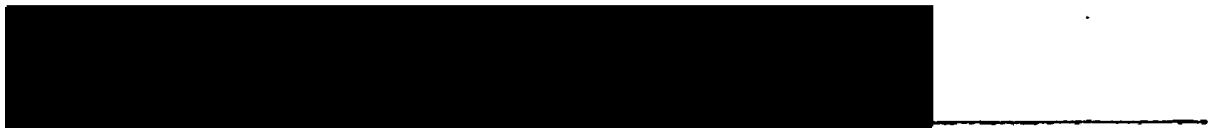
Cord B. Sengztrake

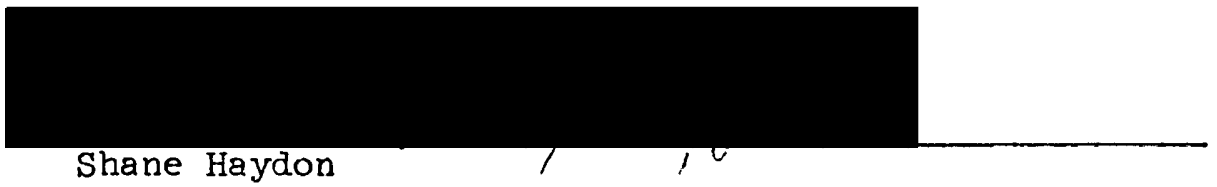

Studies concerning tactile short-term memory (short-term memory for the sense of touch) have often been contradictory. Some of these studies support the existence of modality-specific tactile nemory, a separate, independent storage system for tactile information. Other studies do not support such a system. Further, contusion has arisen regarding the tactile test materials, since many of them use comnon shapes which are easily labeled verbally. It is hypothesized that information which can be labeled is stured in material-specific verbal memory in the left hemisphere, while patterned or spatial information is stored in material-specific nonverbal memory in the right hemisphere. This paper reports two studies conducted to demonstrate both 
verbal and nonverbal material-specific memory using tactile test materials. The first experiment utilized the Seguin Formboard, which has wooden shapes that are easily labeled verbally. The test was administered to brain damaged patients and to normal controls. Results showed that the performance of the people with left hemisphere brain damage was significantly impaired relative to the normal controls. This was expected since verbal material is processed in the left hemisphere. People with damage in this area have difficulty naming objects and storing the names.

The second experiment utilized. wooden shapes that were presumed difficult to label. This test was again administered to brain damaged subjects as well as to normal controls. The results were not significant. Tuis may have been because the test was too difficult or because it did not top nonverbal spatial information. Thus, people with right hemisphere dumage were expected to have difficulty processing this type of material. The right damaged group did tend to do more poorly than the other groups. It is not known if this difference would be significant were the test simplified, or if there were actually no group differences.

The first study suggests that the Seguin Formboard, thought to be a nonverbal tactile memory test, is actually verbally mediated. The second study did not yield significant results, but suggests a line of further research into the area of nonverbal material-specific memory. tested in the tactile modality. These experiments suggest the importance of carefully evaluating test materials to determine what abilities they actually ineasure in order to obtain a fine analysis of memory function. 
MATERIAL-SPECIFIC PROCESSES IN TACTIIE SHORT-TERM MEMORY

by

CHRISIITIA AINNE MEYERS

A thesis submitted in partial fulfillment of the requirements for the degree of

MASTER OF SCIENCE
in
PSYCHOLOGY

Portland State University

1978 
TO THE OFFICE OF GRADUATE STUDIES AND RESEARCH:

The members of the Committee approve the thesis of Christina Anne Meyers presented May 30, 1978.

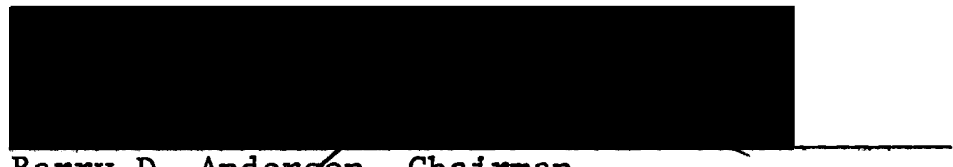

Barry D. Anderfon, Chairman

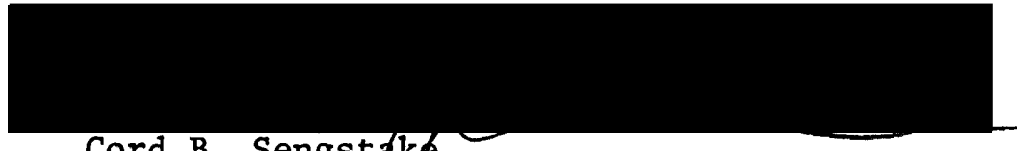

Cord B. Sengstalye

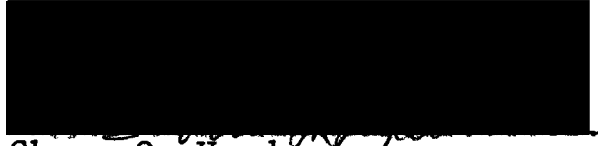

Shane 0. Haydơn

APPROVED :

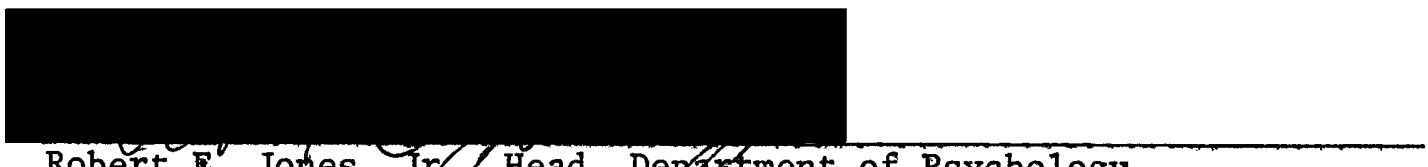

Robert E. Johes, Jr.7 Head, Department of Psychology

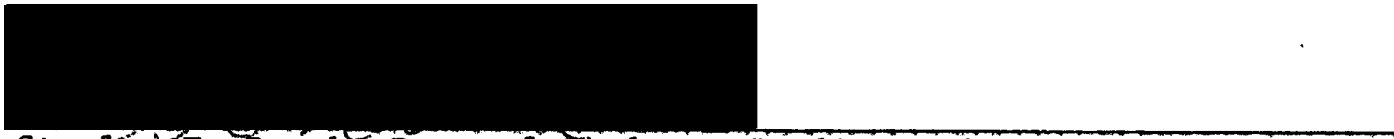

Stanłey E. Rauch, Dean of Graduate Studies and Research 


\section{ACKNOWTEDGMENTS}

I wish to extend my appreciation to Dr. Muriel Lezak for the use of her research material, and to the Portland Metropolitan Stroke Club for their generoiks cooperation. 
TABIE OF CONTENTS

PAGE

ACKNOWLEDGMENTS . . . . . . . . . . . . . . . . iii IIST OF TABIES . . . . . . . . . . . . . . . . . v IIST OF FIGURES . . . . . . . . . . . . . . . . . . . vi vi

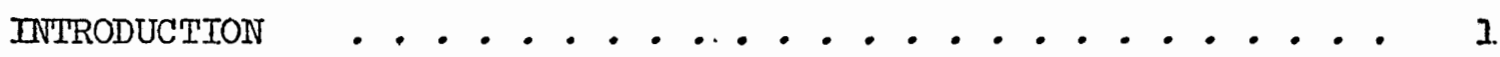

Components of STM ................... 2

Physiological Basis of Material-Specific STM . . . . . 6

Physiological Basis of Modality-Specific STM . . . . . 7 EXPERTMENT 1 . . . . . . . . . . . . . . 26 EXPERTIENT 2 . . . . . . . . . . . . . . . . . 21 GENERAT DISCUSSION . . . . . . . . . . . . . . 25 REFERENCES ....................... 27 


\section{IIST OF TABIES}

TABIE

I Statistical Results for Experiment 1:

Timed Trials . . . . . . . . . . 17

II Statistical Results for Experiment 1:

Memory and Location Scores ... . . . . 17

III Statistical Results for Experiment 2........ 23 


\section{IIST OF FIGURES}

FIGURE

PAGE

1. Short-term Memory Systems (Massaro, 1973) ......... 3

2. Thalamus (Netter, 1972, p. 48) .............. . 7

3. Tactile Memory Task Used by Ghent et al. (1955) . . . . 1 II

4. Shapes of the Seguin Formboard . . . . . . . . 14

5. Means ( $\pm \mathrm{SEM})$ for Site of Lesion, Experiment 1 :

Timed Trials ................. 18

6. Means ( $\ddagger$ SEM) for Hand Used, Experiment. 1:

Timed Trials . . . . . . . . . . . . . 19

7. Means ( $\because$ SEM) for Site of Iresion, Experiment 1:

Memory and Location Scores . . . . . . . . 19

8. Means ( \pm SEM) of AII Trials, Experiment 2 . . . . . . 23 


\section{INPRODUCTION}

Short-term memory (STM) is a transient, unstable irace of very recent events (Horton \& Turnage, 1976, p. 152). Information in this system decays within approximately 30 seconds unless a control process, such as rehearsal, maintains it for a longer period of time (Atkinson \& Shiffrin, 1968). STM is thought to consist of two systems; materialspecific and modality-specific STM. Modality-specific STM is the relatively unprocessed information coming in directly from the senses. A separate, independent storage system is hypothesized for each sensory modality, each of which is processed bilaterally in the brain, that is, equally in both hemispheres. Visual and auditory STM have been studied most extensively. Material-specific STM refers to the storage systems that depend upon the way in which information is coded, verbally or nonverbaliy. The left hemisphere of the brain stores the verbal material, and the right hemisphere stores nonverbal material.

A number of studies have concerned tactile memory (memory for the sense of touch), but findings are contradictory. While some studies suggest there is a tactile memory, as there are visual and auditory memories, others fail to show the existence of a separate tactile memory. Further, some confusion has arisen regarding the tactile test materials, since many of them utilize common shapes (e.g., squares and circles), which are easily labeled verbally. This confounds the modality-specific tactile memory results with a material-specific component. 
This paper will begin by discussing material- and modalityspecific STM, including the possible neuroanatomical correlates of these systems, and then focus on tactile memory. Two studies will be presented on tactile STM; one using common, easily labeled shapes, and one using shapes that cannot be easily labeled. These studies will try to demonstrate both verbal and nonverbal material-specific tactile memory.

\section{COMPONEITS OF STM}

Memory can be discussed in terms of the physical phenomena, such as sound and light, that carry the information to the senses. Massaro (1973) makes the assumption that since memory is closely tied to perception, the dimensions of memory are analagous to the dimensions of sound and light after they are processed in the brain.

Massaro postulates an information-processing model of the processing operations between reception of the initial stimulus and the meaning that is derived from it. First, the stimulus is held in preperceptual storage for approximately $250 \mathrm{msec}$. There is a oneto-one relationship between the stimulus and the information in this system. At this point feature detection occurs, which is the analysis of simple physical attributes such as size, shape, and color. Secondly, higher pattern recognition occurs. This is a transformation of the features held in preperceptual storage into a percept. This. "gestalt" is stored in synthesized memory. Finally, conceptual processing takes place to derive meaning. This information is then stored in generated abstract memory. This memory store contains abstract 
rather than modality-specific information (Massaro, 1975, p. 7-12). Massaro hypothesizes that both synthesized and abstract memory are parts of STM, and that information in either form can be maintained independently (see Figure 1). Synthesized memory is commonly termed modality-specific memory. Generated abstract memory is equivalent to material-specific memory.

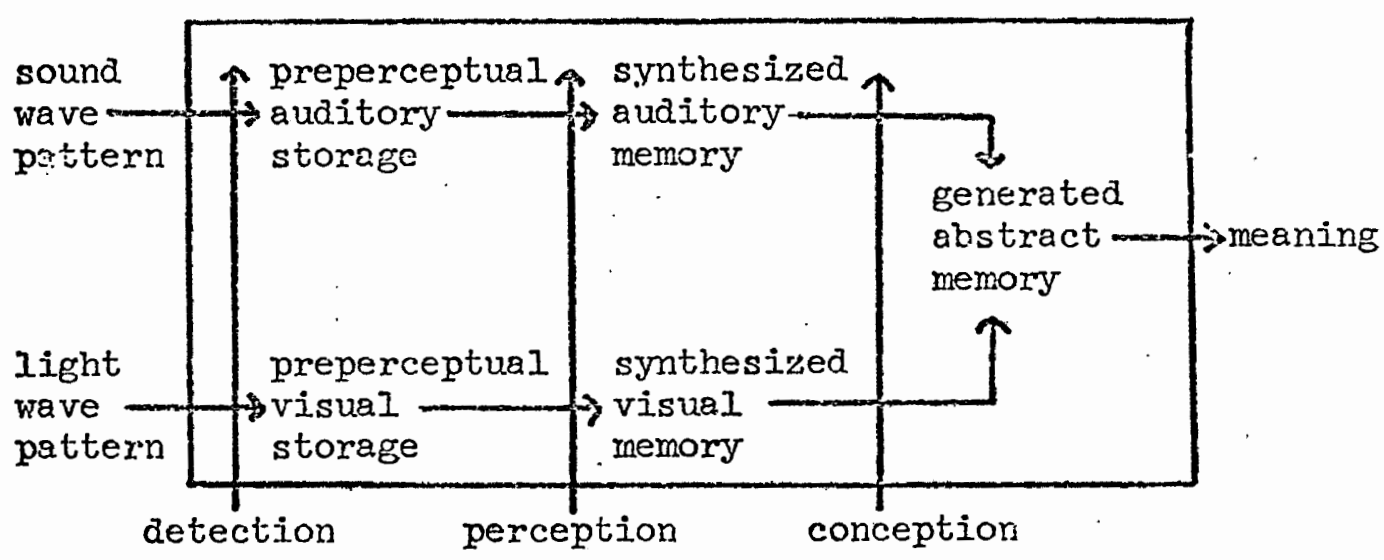

Figure 1. Short-term memory systems (Massaro, 1973).

To test this model, Nassaro (1973) used same-different reaction time tasks. The subjects were presented with two spoken letters, and were to decide if they had the same or different names. The independent variable was whether the two letters were presented by the same or different speakers. Massaro found a faster reaction time on both the same and different name trials when the same speaker articulated the letters. This faster reaction time was independent of a delay between the presentation of the two letters. Massaro suggests the subjects retained the experimenter's voice in synthesized auditory memory and used that information to facilitate recognition of the second letter. 
Massaro found a similar result for visually presented letters. Reaction times were approximately $80 \mathrm{msec}$ faster with physical matches (i.e., letters printed in the same way) than with name matches under a no-delay condition when the letters were printed differently. When an interval was interpolated between the two stimulus letters, the reaction times were the same. Apparently, when a delay is introduced subjects compare the letters on a rame basis; utilizing materialspecific memory. Beller (1967) also found that the response time to physically identical letters was faster than to physically different letters with the same name (i.e., A and E). Posner \& Nitchell (1967) found similar results. Thus, the faster reaction time to physically match letters, as opposed to naming them, points to serial processing of the information in this memory. system, from modality-specific to material-specific memory. If the subjects are instructed to say the names of the Jetters aloud, then the reaction times between physically matching and naming are identical. That is, it takes just as long to recognize three same and three different letters (Ingalls, 1974). Thus, if the instructions are to internally decide same or different, modality-specific memory is tapped, and the physical attributes are compared. If the instructions are to speak the letter names and decide if they are the same or different, material-specific memory is tapped, and the semantic attributes are compared. Massaro (1975, p. 13) also notes that there is probably some overlap of these systems. For instance, modality-specific memory may eliminate alternatives to what is heard (such as shoes or choose). Material-specific memory may note that only shoes is correct semantically (as in "Take off your shoes") 
and feeds back that information into modality-specific store so the word is heard as shoes. Although the information usually goes from percept to meaning, conceptual information may modify perceptual experience.

Massaro (1973) also presented evidence for separate visual and auditory memory stores. Subjects were given a list of first auditory digits, and then visual letters for one presentation. Since STM has a limited capacity, the auditory list should have caused a decrease in. the recollection of the visual list. However, the correct recall for each list was identical. This then suggests the existence of modality specific STM; a separate, independent memory store for each sensory modality: Massaro also noted that in a shadowing task, where subjects first remember a letter presented visually or orally, and then repeat back the auditory Iist, auditory shadowing interfered with the recall of the auditory list much more than the visual shadowing did.

Short-term memory can then be discussed in terms of two systerns: Modality-speciric, slich as visual and auditory memory, and materialspecific, such as verbal and nonverbal memory. There are several behavioral differences that distinguish these systems. Forgetting is very rapid in modality-specific memory (about 5-15 seconds), and is as rapid for filled as for unfilled retention intervals if the interpolated task is in a modality different from the one under observation. Events occuring in other sensory modalities do not affect the modalityspecific memory of a particular modality. Events in the same modality as a given sensory storage system will interfere with it and cause it to be lost (Schurman, et al., 1973). Verbal STM, due to the higher 
level processing of the information, may last up to 30 seconds unrehearsed. In verbal STM, interference comes from several modalities simultaneously. Also, loss from verbal STM is greater when the retention interval is filled with verbal material than with nonverbal material. Investigators are now determining the physical correlates in the brain of these two types of STM.

\section{PHYSTOLOGICAL BASIS OF MATERIAL-SPECIFIC STM}

Fedio \& Van Buren (1972) have implicated the ventrolateral thalamus in verbal and nonverbal short-term memory. The subject population consisted of people undergoing unilateral left or right thalamotomy for relief of Parkinsonism. Each patient had a therapeutic electrode inserted through a medial parietal burr hole into the pulvinar nucleus and the remainder thalamus (anterior and inferior to the pulvinar) (see Figure 2). Each patient was given verbal and nonverbal memory tests. Fedio \& Van Buren found that naming errors were the result of left pulvinar stimulation, that is, the patient was unable to recall the names of common objects correctly identified before the stimulation, even though there were no speech disturbances. These patients had no difficulty with the nonverbal task. "Right pulvinar stimulation produced perceptual discrimination errors with objects correctly perceived before stimulation, but no difficulty with naming or speech. In this case, the patient was unable to recognize complex patterns he identified before the stimulation. Excitation of regions outside the pulvinar nucleus produced no disturbances of memory.

Fedio \& Van Buren also found that at lower levels of stimulation 
verbal and nonverbal memory remained basically intact, but visual STM was disrupted. This results from the recjprocal connections the pulvinar nucleus has with the visual association areas of the cortex (Clark, 1975). Thus, although the thalamus is not a "language center" as such, there may be a system involving the cortex and the thalamus the regulates language in the left hemisphere and nonverbal abilities in the right hemisphere. There has been increasing clinical evidence of patients with thalamic lesions that manifest language disorders (Brown, 1974 and Rikian \& Cooper, 1975).

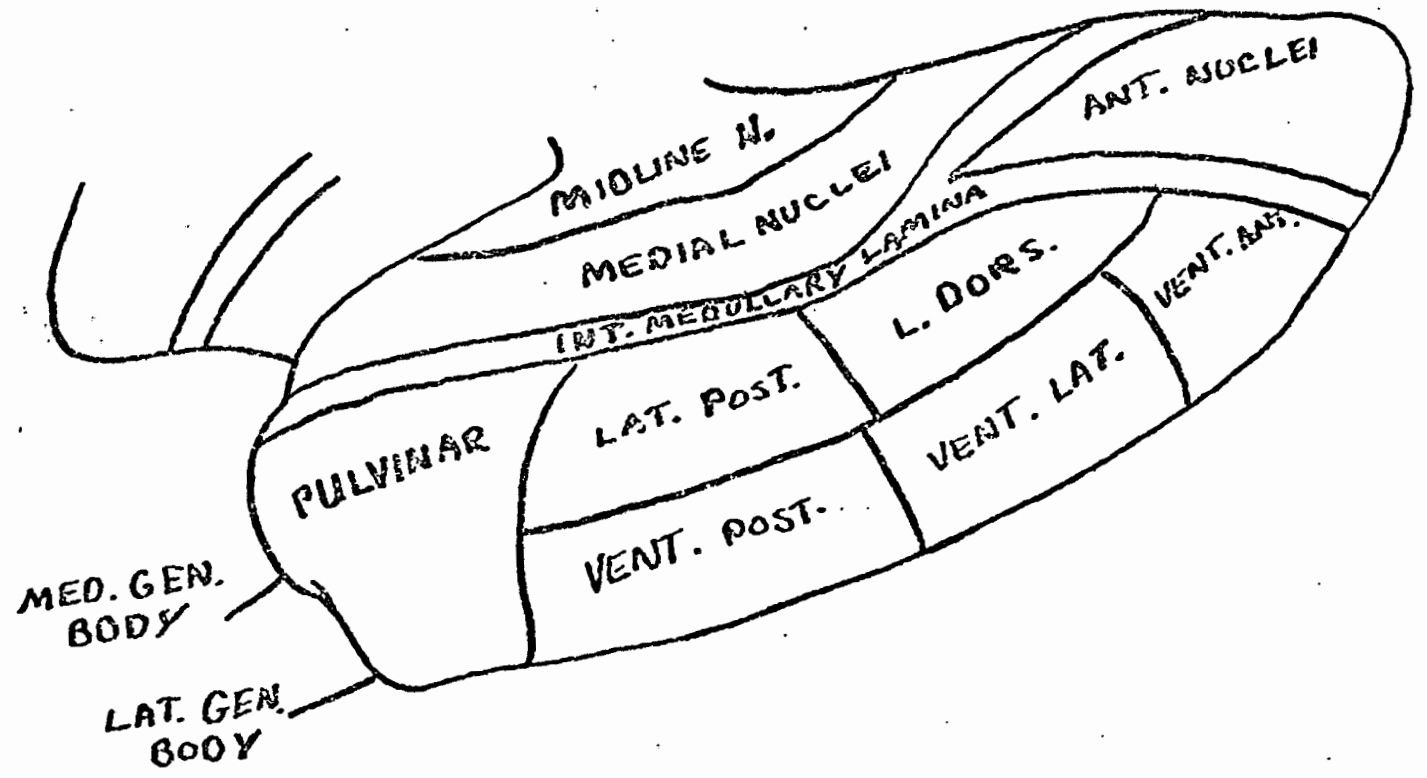

Figure 2. Thalamus (Netter, 1972, p. 48).

PHYSIOLOGICAL BASIS OF MODALITY-SPECIFIC STM

The foregoing indicates that subcortical structures are involved with material-specific (i.e., verbal and nonverbal) STM, and that the left hemisphere processes verbal information and the right hemisphere processes nonverbal information (Fedio \& Van Buren, 1972). There are 
now a large number of studies investigating cortical damage and implicating these lesions in modality-specific memory. lodality-specific memory involves separate, independent storage systems for each sensory modality. These sensory systems contain information in a relatively unprocessed form as compared to verbal memory (Schurman et al., 1973).

\section{Visual STM}

-Butters et al. (1970) investigated patients with left and right parietal lobe damage. The hallmark symptoms of these people include impaired spatial orientation. They are unable to visualize how an object looks from different perspectives. This inability to rotate objects mentally may be just a manifestation of a more basic deficit, the inability to retain visual images. A visual STM disruption vould help explain the various constructional-spatial problems of parietal patients, such as the inability to recognize faces or to reproduce a design with blocks. It is knom that the parietal lobes are involved with the processing and storage of visual information.

Butters et al. (1970) tested the hypothesis of visual memory disruption in parietal lobe damage. The subjects vere presented with a visual or auditory stimulus, and required to identify it after nodelay or a delay of 3,9 , or 18 seconds. If the patient correctly identified the object under the no-delay condition, it suggested that the information was getting into the brain correctly, ruling out a registration difficulty. If both the delay and no-delay condition performances were impaired, perceptual processes were assumed to be disrupted. If the patient was able to perfor $m$ at no-delay, but was unable to perform adequately after a delay, a deficit of memory was 
indicated.

This study compared people with left parietal (LP), left frontal (IF), right parietal (RP), and right frontal (RF) lobe damage, and normal controls (NC). Butters and his coworkers found no group diff-. erences in the ability to identify geometric patterns under the nodelay conditions. The RP and IP groups made significantly more errors under the visuai delay conditions. The performance of the RP group decayed most rapidiy as the delay interval increased from 0-18 seconds, although both the RP and IP groups were significantly impaired. The same results were obtained using visually presented single consonants and consonant trigrams. Butters and his coworkers also found alexic symptoms in the IP group when consonants were presented visually, which introduced a registration deficit for this group. The LP group was also impaired for the consonants presented in the auditory modality because of this language disturbance. Butters hypothesized that the left hemisphere may be involved in both the processing of verbal information in any modality and in the storage of patterned visual material. The major conclusion of this study was that both parietal lobes are involved in the storage of modality-specific visual material.

\section{Auditory STM}

Samuels et al. (1972) did a similar study with patients who had unilateral excisions of the temporal lobes for the relief of epilepsy. Again, the patients were presented with visual and auditory information and asked to identify it immediately or after a delay. The stimuli were visually presented geometric patterns, visually presented 
consonant trigrams, and orally presented consonant trigrams. Samuels and her coworkers found no group effects for visual patterns or visual consonants. With Euditory consonants, they found no differences between the groups under the no-delay condition, but both left temporal (IT) and right temporal (RT) damaged groups made more errors under the delay condition. There were no differences between the IT and RT groups. Both left temporal and right temporal lesions appear to disturb identification of auditory letters, while only left hemisphere lesions disrupt the processing of words. The left hemisphere processes the syntactic-semantic aspects of language, while the more basic acoustic analyses are processed bilaterally. The consonant trigrams used had low association or linguistic value, and were thus similar to nonsense words. These were processed equally in both hemispheres, which indicates modality-specific memory is bilatera. Materialspecific memory is processed only in the hemisphere that handles verbal or nonverbal material.

\section{Tactile STM}

Thus far the discussion of moda].ity-specific memory has been limited to auditory and visual memory. There is also a large body of research on tactile memory, but much of it contains contradictory results.

Ghent et al. (1955) used tactile patterns made of raised metal strips on a wooden block (see Figure 3). The blindfoldea patient feels a sample pattern for 5 seconds and then selects that pattern from the array on the board. Ghent gave each patient six trials:

1. Using hand ipsilateral to the lesion. 
2. Using hand contralateral to the lesion.

3. Contralateral hand.

4. Ipsilateral hand.

5. Ipsilateral hand.

6. Contralateral hand.

The patient's score was the number of correct choices made. Among the noxmal controls, there were fewer errors on Trial 3 than for Trial I, which indicates learning. Among the brain damaged patients, the ipsilateral hand showed improvement over trials 1, 4, and 5, but the contralateral hand did not show improvement. Among the controls, the improvement between their own ipsilateral and cortralateral hands was not significant, but there was a difference between the performance of the ipsilateral and contralateral hands in the brain damaged group.

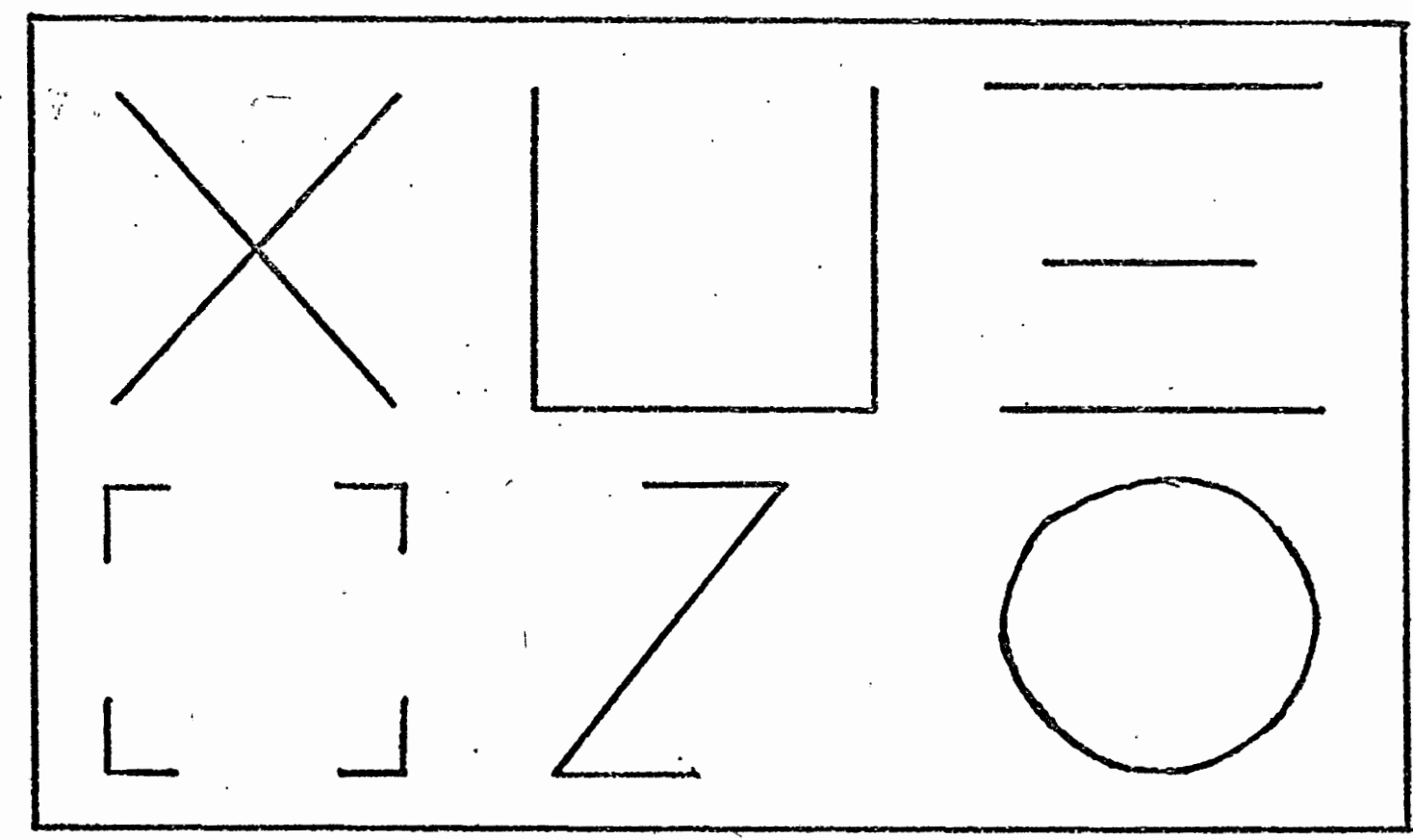

Figure 3. Tactile memory task used by Ghent et al. (1955).

Ghent and her coworkers at first thought the lack of improvement in the brain damaged contralateral hand was due to sensorimotor disturbance. 
They then divided the patient group into those with somesthetic or motor defects of the hand, and. those with no such defects. The contralateral hand still showed no improvement in either group, while the ipsilateral hand improved in both groups. Ghent then divided the patient group into various other categories, such as locus of lesion, presence of aphasia, or presence of epilepsy. None of these subgroups showed improvement in the hand contralateral to the brain damage, while all improved with the ipsilateral hand. Ghent et al. (1955) describe this tactile memory impairment in the contralateral hand as a difficulty in learning, but it could also be thought of as a deficit of tactile modality-specific STM. Ghent found that a lesion anywhere in one hemisphere caused this impairment. This would seem to rule out a specific location within the brain that handles tactile material.

Schurman et al. (1973) investigated memory for two successive touches on the arm to determine if the interval between the touches and the presence or absence of an interpolated task in this interval affected tactile memory as it does visual memory. They found a gradual decrease in correct recall for both filled and unfilled intervals over time. Events occuring in other modalities, such as auditory counting, did not affect performance. This study supports modalityspecific memory for touch. However, Helgoe (1972), also working with touches to the forearm, found that recall was negatively affected by counting backward during the retention interval.

The interpolated task also interfered with tactile memory in a study by J. Clark (1974). When subjects were given a tactile pattern 
to retain, they made more errors when a visual search task was interpolated in the retention interval. When a tactile search task was introduced in the interval, performance also deteriorated, but not as much as with the visual search. Clark presented two possible explenations for his results. First, the tactile pattern was somehow coded and stored in visual STM. The alternative explanation was that both visual and tactile information were coded in some combination. Clark may have instead tapped material-specific nemory for nonverbal tactile patterns. This would account for the interference from the visual task:

A common tactile memory test used by clinicians is the seguin Formboard. This test is commonly thought to test nonverbal tactile memory. The test consists of ten wooden shapes placed in appropriate holes in a wooden board (see Figure 4). Each patient is blindfolded, and the shapes are placed in front of the formboard within easy reach. The patient, using first his preferred hand (PI), places the shapes into their appropriate holes. The score is the time to place all ten shapes, in seconds. The second trial is with the subject's nonpreferred hand (NP). Both hands (B) are used for the third trial, and finally the preferred hand (P2) for the last trial. The test materials are then removed and the patient unblindfolded. The patient is then asked to draw on a piece of paper the shapes (memory score) and their approximate locations on the board (location score).

Some investigators have found that left hemisphere damaged patients do better than right damaged patients on the blindfolded task, but right damaged patients do better on the recall task. The better recall 
of the right damaged patients may be aue to the ease with which the shapes may be labeled, utilizing verbal memory (Lezak, 1976, p. 381). Lezak also notes (p. 383) that if trial PI takes about $420-480$ seconds and trial NP takes about 180-300 seconds, a left hemisphere lesion is indicated. If trial NP takes longer than trial $\mathrm{P}$, but trial $B$ is shorter and the memory score is adequate, a right hemisphere lesion is indicated.

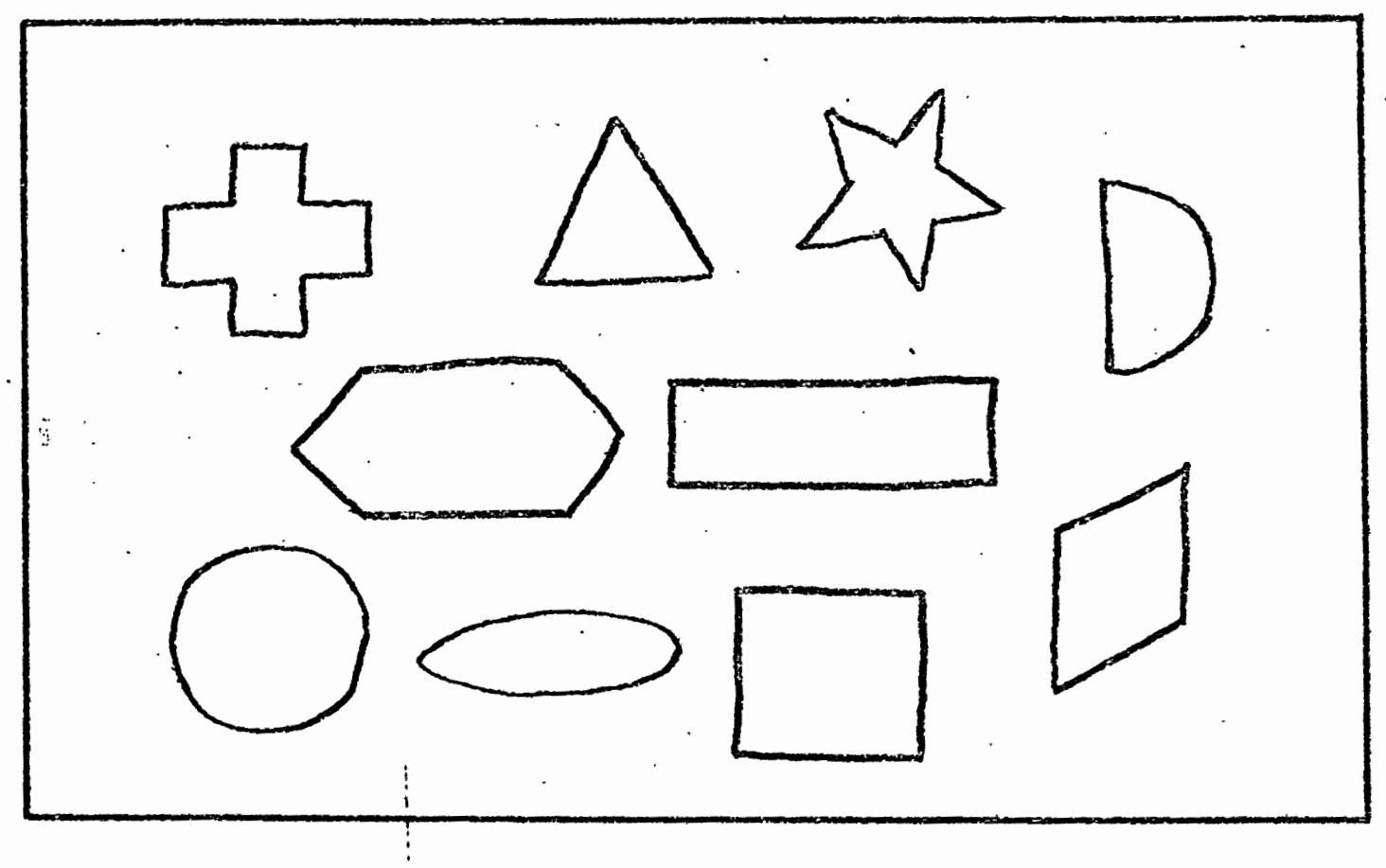

Figure 4. Shapes of the Seguin Formboard.

There is some controversy concerning the type of brain damage to which the Seguin Formboard is most sensitive. Reitan (1964, p. 308) reported his frontal lobe damaged groups performed worse than the non-frontal groups. He found differences between right frontal and left nonfrontal groups, and between left frontal and right nonfrontal groups, which is not an appropriate comparison (Iezak, 1976, pl 382). 
Reitan also found differences between left frontal and right frontal groups on Trials NP, B, and total time score. He did not find. differences between the frontal and nonfrontal groups within the same hemisphere. Reitan also found that the left damaged groups did better with their ipsilateral hand, which is consistent rith the findings of Ghent et al. (1955).

Teuber (1964, p. 421) found that the nonfrontal groups did worse than the frontal groups on both the formboard task and memory scores. Other researchers have also found the frontal groups to perform better (Lezak, 1976, p. 382).

Because of the contradictory nature of the research on tactile memory, and the lack of distinction between modality-specific and material-specific tactile memory, the following two studies seek to determine how brain damaged groups process tactile material that can be labeled verbally and tactile material that cannot be labeled verbally. These studies will investigate the possibility of the existence of material-specific tactile memory for both verbal and nonverbal material. 


\section{EXPERIMENT I}

The purpose of this experiment was to demonstrate materialspecific tactile memory for verbal material.

\section{Method}

Subjects. Twenty-seven subjects were selected from a population of brain damaged people being tested in an ejght-year longitudinal study conducted by Dr. Muriel Lezak at the Portland VA Hospital. Nine of the patients had left hemisphere damage, nine patients had right hemisphere damage, and nine patients had bilateral-diffuse damage. The experimental subjects (all males) ranged in age from 20 to 47 , with a mean age of 28. Twenty-one had brain damage as a result of traumatic injury, 3 from cerebral-vascular accidents, and one each from infection, tumor, and anoxia. Neurological reports and the side of hemiparesis, if any, were used to group the subjects into left, right, or bjlateral diffuse categories. Nine subjects were also tested as normal controls. These subjects (all males) ranged in age from 19 to 39, with a mean age of 26 .

Procedure. Each patient was given the Seguin Fomboard test in accordance with the standard administration as described previously. Scores were obtained for trials $P I, N P, B$, and $P 2$, memory, and location for each subject. Differences between the left and right hemisphere damaged groups were expected since the Seguin forms are easily labeled 
verbally, which the right damaged people might utilize to facilitate recall.

\section{Results and Discussion}

The statistical analysis used was the two-way analysis of variance with repeated measures on one factor. Statistical results of this experiment are presented in Tables I and II. There was a significant difference between the performance of the different experimental groups on the timed trials (p $<.05$ ).

TABLE I

STATISTICAL RESULTS FOR EXPERIMENT I TIMED TRIAIS

\begin{tabular}{|c|c|c|c|c|}
\hline $\begin{array}{l}\text { Between Subjects } \\
\text { ite of Lesion } \\
\text { irror }\end{array}$ & $\begin{aligned} \frac{S S}{.211} \\
483253.47 \\
.1624\end{aligned}$ & $\begin{array}{r}\frac{D F}{35} \\
3 \\
32\end{array}$ & $\begin{array}{c}\text { MS } \\
16.1084 .49 \\
50756.96\end{array}$ & $\begin{array}{l}\underline{F} \\
3.17(\underline{p}<.05)\end{array}$ \\
\hline $\begin{array}{l}\text { ithin Subjects } \\
\text { and Used } \\
\text { ateraction } \\
\text { cror }\end{array}$ & $\begin{array}{r}.1924 \\
964071.138 \\
75875.58 \\
884534.78\end{array}$ & $\begin{array}{r}108 \\
3 \\
9 \\
96\end{array}$ & $\begin{array}{c}321357.046 \\
8430.62 \\
9213.90\end{array}$ & $\begin{array}{c}34.87(\underline{p}<.001) \\
.91 \text { (N.S.) }\end{array}$ \\
\hline
\end{tabular}

TABLE II

STATISTICAL RESULTS FOR EXPERIMENT I MEMORY AND LOCATION SCORES

\begin{tabular}{|c|c|c|c|c|}
\hline $\begin{array}{l}\text { Between Subjects } \\
\text { Site of Lesion } \\
\text { Error }\end{array}$ & $\begin{array}{c}\text { SS } \\
372.611 \\
82.50 \\
290.111\end{array}$ & $\begin{array}{r}\frac{D F}{35} \\
3 \\
32\end{array}$ & $\begin{array}{l}\text { MS } \\
27.50 \\
9.065\end{array}$ & $\begin{array}{l}\underline{F} \\
3.03(\underline{p}<.05)\end{array}$ \\
\hline $\begin{array}{l}\text { Within Subjects } \\
\text { Memory/Location } \\
\text { Interaction } \\
\text { Error }\end{array}$ & $\begin{array}{r}172.00 \\
112.50 \\
6.28 \\
53.22\end{array}$ & $\begin{array}{r}36 \\
1 \\
3 \\
32\end{array}$ & $\begin{array}{r}112.50 \\
2.09 \\
1.66\end{array}$ & $\begin{array}{c}67.64 \\
1.25 \\
(\text { p. }(.001)\end{array}$ \\
\hline
\end{tabular}

A further analysis using the Newman-Keuls test showed that the 
left damaged group was significantly impaired relative to the normal control group $(\underline{p}<.05)$. No other comparisons between groups proved to be significant (see Figure 5). On the memory and location scores, the left damaged group was significantly impaired relative to the right damaged and control groups $(\underline{p}<.05)$. The bilateral-diffuse group was also significantly impaired reletive to the controls $(\underline{p}<.05)($ see Figure 7$)$.

The overall time taken for each trial was significantly different ( $\underline{p}<.001$ ), except for trials $P 2$ and $B$, which did not differ (see Figure 6). The interaction between the site of damage and each trial was not significant. The number correct for the memory and location scores differed significantly $(\underline{p}<.001)$, favoring the memory scores. There was no interaction between the site of damage and. the memory or Jocation scores.

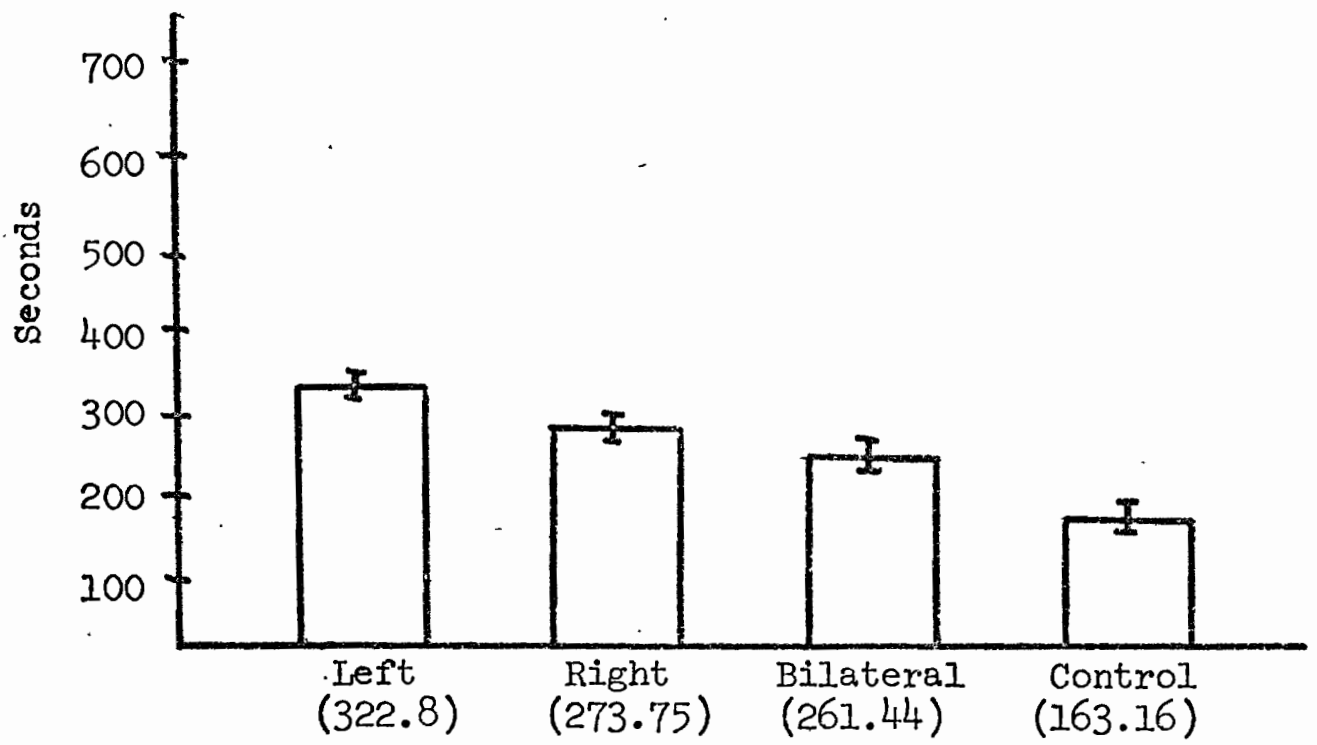

Experimental Group

Figure 5. Means ( \pm SEM) for site of lesion, Experiment I, timed trials. 


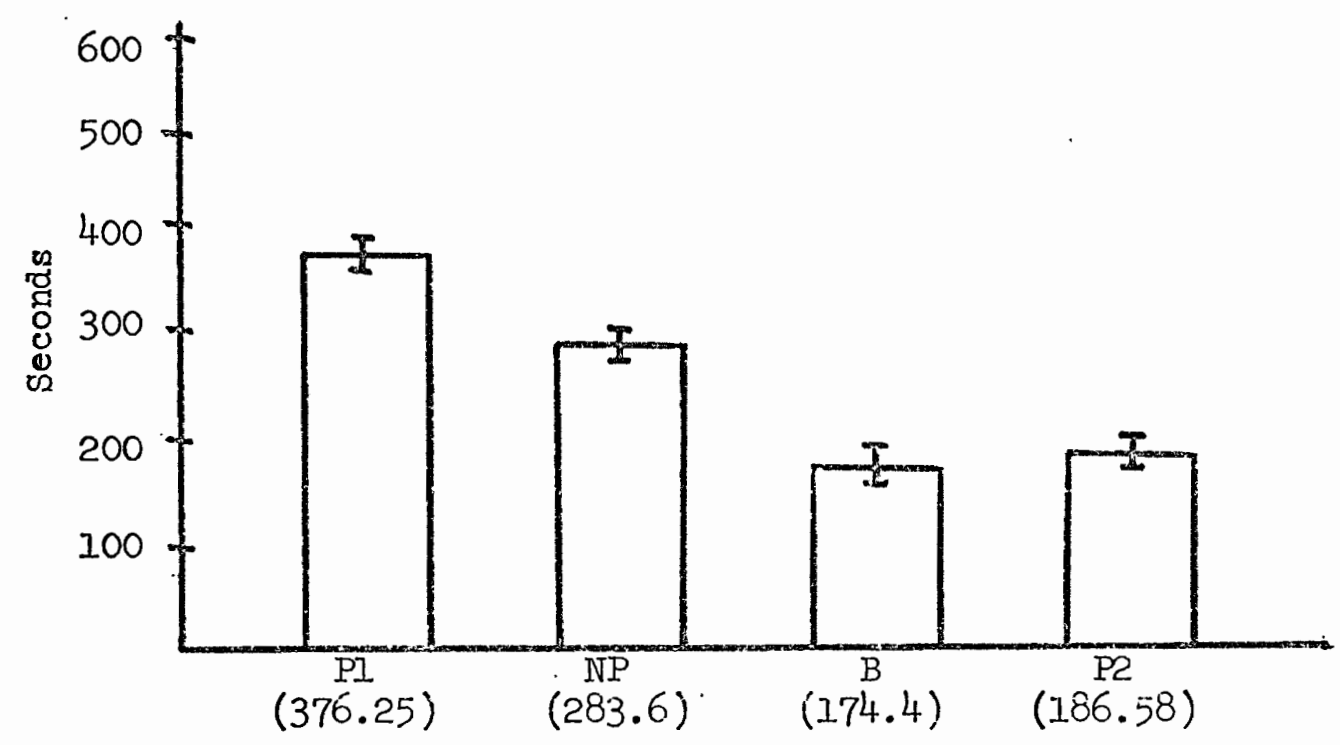

Trial

Figure 6. Means ( $\$$ SEM) for hand used, Experiment 1, timed trials.

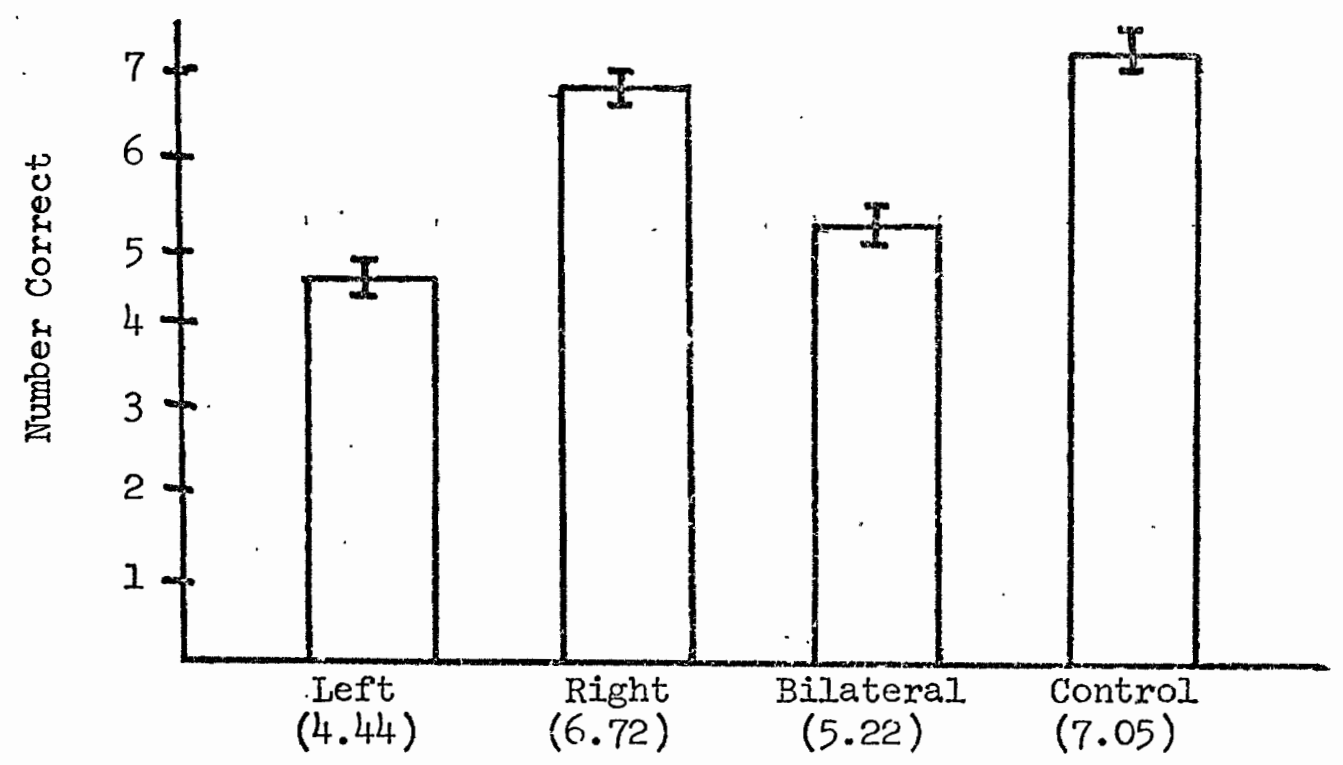

Experimental Group

Figure 7. Means (it SEM) for site of lesion, Experiment 1, memory and location scores. 
These results suggest the Seguin Formboard taps verbal shortterm memory. The people with right hemisphere lesions and the control group were able to label the Seguin shapes verbally to facilitate recall, while the left hemisphere damaged people were unable to do so. The Seguin Formboard has been traditionally considered a test of nonverbal skills, which this study seriously questions. The following study investigates an alternative test specifically designed to assess nonverbal abilities. 


\section{EXPERTMENT 2}

Method

Subjects. Twelve subjects volunteered from the Portland Metropolitan Stroke Club, Portland, Oregon. Half of these people had left hemisphere strokes, and half had right hemisphere strokes. The experimental subjects ( 9 males and 3 females) ranged in age from 44 to 67, with a mean age of 57 . The site of damage was determined by the side of hemiparesis, if any, presence of aphasia, and verbal reports from the subject or his family. Another six normal control subjects were also tested. The control group ranged in age from 46 to 75 , with a mean age of 62 .

Procedure. Each subject was first given a tactile acuity test to determine if his sense of touch was adequate for the tactile memory test. This also determined if the tactile information was being received in the brain correctiy. The test consisted of having the subject feel two wooden shapes concealed behind a curtain. The tactile materials consisted of 6 three-dimensional shapes made by gluing five wooden cubes ( $3 / 4$ in. sq.) into various configurations. The subject judged whether the shapes felt alike or different. There were three trials under this no-delay condition.

The subject was then presented with a sarmple shape, concealed abehind a curtain. He felt the shape with the hand ipsilateral to the stroke for as long as desired (control subjects used their preferred 
hand). After a 5-second delay, the subject was then asked to pick out that same shape from an array of six different shapes behind the curtain. The subject was then given another sample shape to feel behind the curtain, and asked to identify it visually from the array of six shapes after a 5-second retention interval. Three trials were given under both the tactile-tactile and the tactile-visual conditions. The score for each condition was the number of correct choices made, ranging from $0-3$ for each condition. A tape of hospital pages was played throughout the test to help confound any attempts at verbalization.

It was expected that the right hemisphere damaged group would be impaired relative to the left damaged and control groups. These shapes are primarily spatial, and any attempts to verbalize them would be inefficient. The left damaged and control groups would use their nonverbal memory store to retain the information.

Results and Discussion

A two-way analysis of variance with repeated measures on one factor was used to analyze the data. Statistieal results for Experiment 2 are presented in Table III. The site of damage did not significantly affect performance, although the differences were in the predicted direction (see Figure 8). The right damaged subjects tended to do more poorly than either the left damaged group or normal controls. The right damaged group also tended to go more slowly during the test and to use cues such as the number of grooves in the shape to facilitate recall. Several subjects in this group tried to 
scratch the surface of the design to leave an identifying mark.

\section{TABIF III}

STATISTICAI RESUTTS FOR EXPERIMENT 2

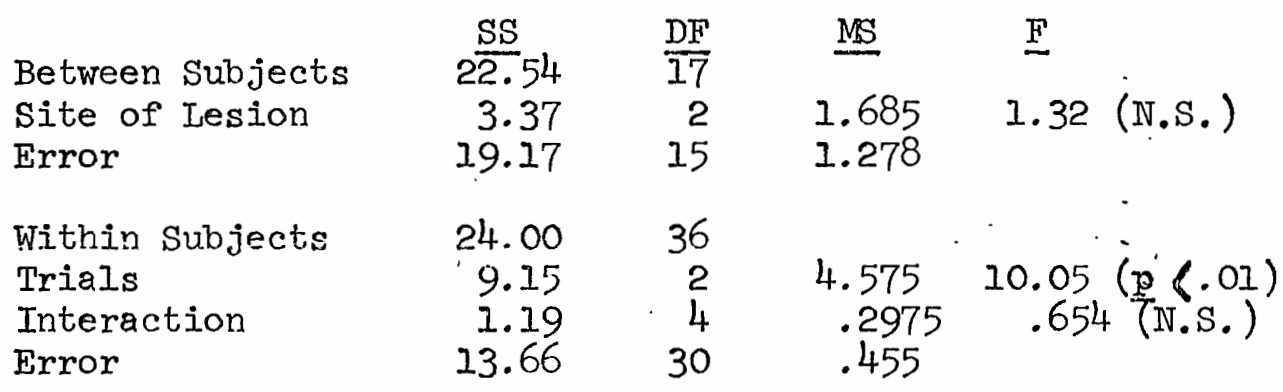

The performance under the two memory trials differed significantly (p<.OI) from the no-delay condition. The tactile-tactile and tactilevisual conditions did not differ significantly. This was expected if material-specific memory was being tapped, since this system stores information from all sensory modalities.

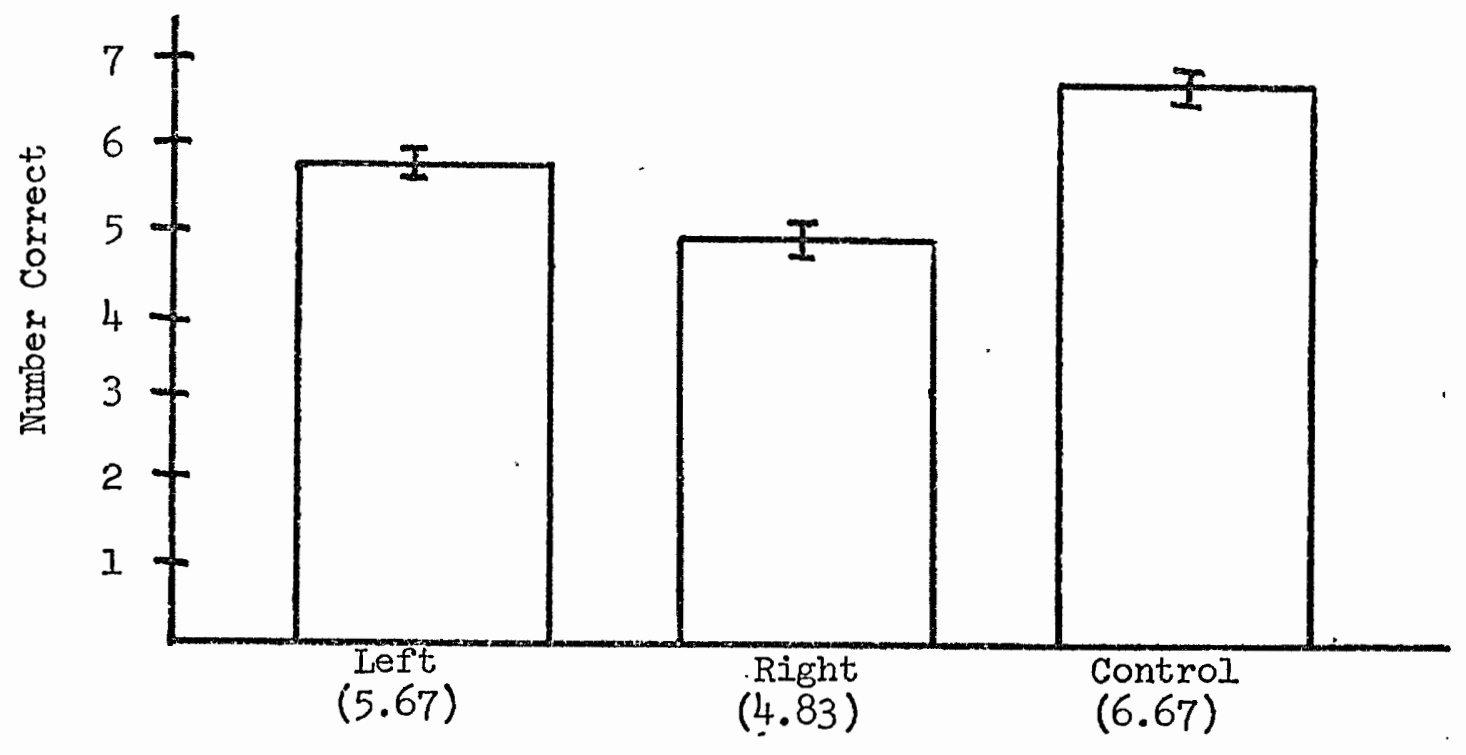

Experimental Group

Figure 8. Means ( \pm SEM) of all trials, Experiment 2. 
There are several possible factors that might account for the lack of significant differences between experimental groups. One is that the procedure and test designs were too difficult for a large distribution of performance to be seen. In fact, the average per cent correct across all conditions and groups was 63. OnIy one subject in the control group performed at $100 \%$ correct, and one scored 35\% correct. If the test figures and procedure vere redesigned to yield a wider distribution of performance, significant differences may appear between the groups. The significant difference between the no-delay and delay conditions would probably remain stable, since it reflects that the minimum ability necessary to take the test (ie., tactile acuity) is not dependent upon memory function.

Another reason for the lack of significant differences in this study may have been the age of the subjects. The ages ranged from 44 to 75 years, and the older subjects tended to perform more poorly regardless of which experimental group they were in. 


\section{GENERAL DISCUSSION}

Material-specific tactile memory for verbal material was demonstrated in Experiment 1. Since verbal material is processed and stored in the left hemisphere, people with damage in this area have difficulty with labeling and storing these verbal labels. This experiment also suggests that the Seguin Formboard, thought to be a nonverbal tactile memory test, is verbally mediated. It is of great importance that clinicians are aware of what a given test actually measures, otherwise the results obtained may be very misleading and cause problems in the diagnosis of organic or functional disorders. Material-specific tactile memory for nonverbal material was not demonstrated in Experiment 2. As previously discussed, the difficulty of the test and the age of the subjects may have obscured any real differences between the experimental groups. A similar test with simpler figures may indicate whether this test is indeed sensitive to right hemisphere damage, suggesting a nonverbal memory component, or if material-specific nonverbal memory is not being examined. Another possibility is that material-specific nonverbal memory is not Iocated in the right hemisphere.

The results in Experiment 1, using the Seguin Formboard, were obtained from timed trials, while the results from Experiment 2 were obtained from the number of correct decisions made by the subjects. The two studies may be made more comparable if Experiment 2 was modified to be a timed task. In this case, the test itself could be 
performed at $100 \%$ accuracy by all subjects, but the time taken to complete the task may vary by experimental group.

The most important conclusion of these studies is the questioning of the adequacy of memory tests, or tests in general. In the clinical evaluation of memory function, discriminative testing will yield valuable clues as to the locus of the brain damage, the amount of intellectual and behavioral compromise, and the types of remedial treatments that would be most effective. Thus, it is of utmost importance to have a clear understanding of what the memory tests actually measure in order to obtain an accurate and fine analysis of memory functioning. 


\section{REFERENCES}

Atkinson, R. C. \& Shiffrin, R. M. Human memory: A proposed system and its control processes. The Psychology of Learning and Motivation. New York: Academic Press, 1968.

Beller, H. K. Parallel and serial stages in matching. Journal of Experimental Fsychology, 1970, 84, 213-19.

Brown, J. W. Language, cognition, and the thalamus. Confinia Neurologica, 1974, 36, 33-60.

Butters, N., Samuels, I., Goodglass, H., and Brody, B. Short-term visual and auditory memory disorders after parietal and frontal lobe damage. Cortex, 1970, VI, 440-459.

Clark, J. I. Short-term memory for visual and tactual patterns: The effects of information processing load and interpolated task modality. Thesis submitted to the University of Cincinnati, 1974. Dissertation Abstracts InternationaI, 1974, 35, 3053-4.

Craik, F. I. M. Short-term storage in a 'levels of processing' framework. Paper presented at the meeting of the Midwestern Psychological Association, Chicago, 1973.

Fedio P. \& Van Buren, J. Electrical stimulation of thalamic mechanisms for immediate memory in man. Paper presented at the annual meeting of the Anerican Psychological Association, Honolulu, Hawaii, 1972.

Ghent, I., Weinstein, S., Semmes, J., and Teuber, H.-I. Effect of unilateral brain injury in man on learning of a tactual discrimination. Journal of Comparative and Physiological Psychology, 1955, 48, 478-481.

Helgoe, R. Effects of repetition in tactile memory. Thes is submitted to the University of Illinois at Urbana-Champaign, 1971. Dissertation Abstracts International, 1972, 32, 6077.

Ingalls, R. P. Effects of same-different patterns on tachistoscopic recognition of letters. Journal of Experimental Psychology, $1974,102,209-214$.

Horton D. \& Turnage, T. Human learning. Englewood Cliffs, New Jersey: Prentice-Ha11 Inc., 1976. 
Lezak, M. D. Neuropsychological assessment. New York: Oxford University Press, 1976.

Massaro, D. W. The dimensions of short-term memory. Paper presented at the meeting of the Midwestern Psychological Association, Chicago, 1973.

Massaro, D. W. (ed.) Understanding language. New York: Academic Press, 1975.

Netter, F. H. CIBA collection of medical illustrations, Vol. I: The nervous system. CIBA Pharmaceutical Co., 1972.

Posner, M. I. \& Mitchell, R. F. Chronometric analysis of classification. Psychology Review, 1967, 74, 392-409.

Reitan, R. M. Psychological deficits resulting from cerebral lesions in man. In J. M. Warren \& K. Akert (eds.) The frontal grsmular cortex and behavior. New York: McGraw Hill, 1964.

Riklan M. \& Cooper, I. S. Psychometric studies of verbal functions following thalamic lesions in humans. Brain \& Language, 1975, 2. $45-64$.

Samuels, I., Butters, N., and Fedio, P. Short-term memory disorders following temporal lobe removals in humans. Cortex, 1972, VIII, 283-298.

Schurman, D. I., Bernstein, I. H., and Proctor, R. W. Modalityspecific short-term storage for pressure. Bulletin of the Psychonomic Society, 1973, I, 71-74.

Teuber, H. -I. The riảle of frontal lobe function in man. In J. M. Warren \& K. Akert (eds.) The frontal granular cortex and behavior. New York: McGraw Hill, 1964. 